\title{
Práticas de organização e tratamento da informação em órgãos oficiais de perícia criminal: novos cenários para a atuação do profissional da informação
}

\author{
Organization practices and information treatment in official criminal expert institutions: \\ new scenarios for the performance of the information professional
}

\author{
Raimunda Fernanda dos Santos \\ Doutora em Ciência da Informação \\ Universidade Federal do Rio de Janeiro \\ nandaflorania@gmail.com \\ Lehi Bezerra Aguiar \\ Graduado em Biblioteconomia \\ Universidade Federal do Rio Grande do Norte \\ lehi_aguiar@hotmail.com
}

\section{Resumo}

Estuda as atividades que podem ser desempenhadas pelo Bibliotecário no campo da perícia criminal, com base em suas competências e habilidades. Tem como objetivo geral evidenciar as principais tarefas que podem ser desenvolvidas por esse profissional em Órgãos Oficiais de Perícia Criminal no que diz respeito à organização, tratamento e recuperação da informação. Utiliza como metodologia a pesquisa bibliográfica e documental com abordagem exploratório-descritiva a partir de dados extraídos da Classificação Brasileira de Ocupações do Perito Criminal e do Bibliotecário, bem como da aplicação de entrevista semiestruturada a dois profissionais que atuam na Perícia Criminal. Apresenta atividades que podem ser desempenhadas pelo Bibliotecário para contribuir com as atividades realizadas pelos Peritos Criminais nesses órgãos. Essas atividades possuem relações entre si e contribuem para os processos de organização, representação e recuperação da informação nessas instituições. Conclui ressaltando que todas as tarefas apresentadas precisam estar correlacionadas ao saber fazer do Bibliotecário, cabendo a esse profissional agregar as dimensões da competência (conhecimentos, habilidades e atitudes) em qualquer ambiente de trabalho, inclusive em Órgãos Oficiais de Perícia Criminal.

\section{Palavras-chave}

Bibliotecário - habilidades. Bibliotecário - competências. Organização da Informação - Perícia Criminal. Tratamento da informação - Perícia Criminal. Órgãos oficiais de perícia criminal.

\begin{abstract}
Studies the activities that can be performed by the Librarian in the field of criminal expertise, based on his skills and abilities. General objective is to highlight the main tasks that can be performed by this professional in the Official Criminal Expertise Bodies with regard to the organization, treatment and recovery of information. The methodology uses bibliographic and documentary research, with an exploratory-descriptive approach, based on data extracted from the Brazilian Classification of Occupations of Criminal Experts and Librarians, as well as the application of semi-structured interviews to two professionals working in Criminalistics. Presents activities that can be performed by the Librarian to contribute to the activities carried out by Criminal Experts in these bodies. These activities are re-
\end{abstract}


lated to each other and contribute to the organization, representation and information retrieval processes at these institutions. Concludes by emphasizing that all the tasks presented must be correlated with the librarian's know-how, and it is up to this professional to add the dimensions of competence (knowledge, skills and attitudes) in any work environment, including criminal expertise.

\section{Keywords}

Librarian - skills. Organization of Information - Criminal Expertise. Knowledge Organization - Criminal Expertise. Official criminal expert bodies.

\section{INTRODUÇÃO}

Os sistemas econômicos da sociedade, as mudanças nos processos de produção, o advento de novas tecnologias e a criação de novos produtos e serviços são alguns dos fatores que promovem o surgimento de novas profissões. Essas profissões desempenham atividades especializadas e necessitam de transformações/adaptações/atualizações para atender às demandas sociais, caso contrário podem experienciar a perda de postos de trabalho, levando em conta diversos fatores como o desenvolvimento tecnológico, a automatização, entre outros.

Com o desenvolvimento das Tecnologias de Informação e Comunicação (TICs), surgem, progressivamente na sociedade, novas procuras para o preenchimento de cargos de profissionais com competências (conhecimentos, habilidades, atitudes e valores) associadas à organização, tratamento e recuperação da informação, sobretudo em ambientes digitais.

Le Coadic (1996, p. 5), um dos autores que discute esse termo, afirma que "A informação é um conhecimento inscrito (gravado) sob a forma escrita (impressa ou numérica), oral ou audiovisual.". Nessa perspectiva, a informação é disseminada e requisitada com rapidez pelos seus usuários em diversos suportes (analógicos ou digitais) e formatos (áudios, textos, imagens vídeos, etc.), apresentando desafios às instituições e aos novos ambientes de atuação dos profissionais, sobretudo em tempos de pós-verdade ${ }^{1}$ e alta incidência de fake news².

O Bibliotecário, como profissional da informação, possui competências e habilidades essenciais para atuar em diversos ambientes que necessitam de organização, representação, difusão, recuperação, acesso, preservação e uso da informação. Esse profissional possui competências para desempenhar novos serviços de informação demandados pela sociedade, bem como para ocupar novos espaços de atuação, tendo em vista a complexidade para a recuperação e acesso às informações confiáveis que demonstram integridade dos fatos ocorridos e registrados.

As mudanças são inevitáveis para todas as profissões que desejam permanecer no mercado e que se demonstram capazes de atuar em novos cenários. No hodierno contexto informacional, por exemplo, o Bibliotecário, que antes só atuava em bibliotecas, tem outros nichos de mercado em virtude das suas competências técnicas e profissionais, sobretudo no que diz respeito às práticas de organização, tratamento e recuperação da informação.

\footnotetext{
${ }^{1} \mathrm{~A}$ Pós-verdade consiste na relativização da verdade, na suspensão completa da referência a fatos e verificações objetivas, substituídas por opiniões, observações, interpretações (inerentes à cognição humana) tornadas verossímeis e plausíveis apenas à base de repetições, sem que as suas respectivas fontes sejam confirmadas (SANTOS et al., 2019).

${ }^{2}$ Notícias falsas. Distribuição deliberada de desinformação, resultando na modificação direta das relações entre a verdade e a mentira (SANTOS et al., 2019).
} 
As atividades de organização e tratamento da informação se configuram como operações que viabilizam a criação de pontos de acesso descritivos e temáticos para fins de recuperação de objetos informacionais ${ }^{3}$ em sistemas de recuperação da informação. Essas operações são associadas às práticas e técnicas de representação descritiva e temática dos registros e contribuíram para o advento de investigações no campo da Organização do Conhecimento como domínio de estudos teóricos e aplicados essenciais na Ciência da Informação.

A representação descritiva centra-se na descrição dos dados físicos dos materiais informacionais (como autor, ano de publicação e dados similares) a fim de contemplar os aspectos mais objetivos, representando a estrutura desses recursos a partir da atividade de catalogação. Em nítido contraste, o tratamento temático visa descrever o conteúdo (assunto) dos materiais informacionais a partir de operações como a indexação e a classificação, as quais possuem "[...] uma força de carga subjetiva, pois como o nome indica, visam caracterizar o documento do ponto de vista do seu conteúdo." (DIAS; NAVES, 2007, p. 9).

As organizações que podem se beneficiar das competências e habilidades do Bibliotecário são as instituições criminalísticas, as quais trabalham com a informação para fins de elucidação de crimes e são "[...] responsáveis pela constatação da materialidade e da autoria dos fatos criminosos, principalmente no que tange à confiabilidade e certeza da prova por eles produzida." (CUNHA, 2012, p. 14). Acredita-se que esse profissional pode auxiliar os peritos criminais na elucidação de crimes a partir de processos, produtos e instrumentos de organização, tratamento e recuperação da informação.

Os peritos criminais são profissionais que analisam cenas criminais, colhendo, registrando e armazenando amostras como manchas de sangue no carpete, fotografias forenses ${ }^{4}$, resíduos de armas de fogo, entre outros, no intuito de assegurar a prova técnica ou prova pericial mediante análise científica dos vestígios do delito ${ }^{5}$. No campo da perícia criminal, essas amostras consistem em artefatos informacionais e servem como fontes de informação para evidências, podendo também ser trabalhados para auxiliar em inferências, conclusões e tomadas de decisão nas instituições criminalísticas.

Nesse entendimento, tais amostras podem ser trabalhadas pelos peritos em parceria com o Bibliotecário mediante as atividades de representação para fins de recuperação das informações, trazendo à luz a verdade dos fatos. Portanto, acredita-se que o profissional da informação pode ser imprescindível no auxílio e no sucesso das práticas forenses em Órgãos Oficiais de Perícia Criminal.

Com base nessa perspectiva, surge o seguinte questionamento: considerando que a perícia criminal consiste em um exercício técnico-científico substancial para a elucidação de crimes quando houver vestígios, de que maneira o Bibliotecário pode contribuir para a organização, o tratamento e a recuperação de tais vestígios como fontes de informação?

Objetivando responder esse questionamento a pesquisa tem como objetivo geral evidenciar as principais atividades que podem ser desempenhadas pelo profissional Bibliotecário em Órgãos Oficiais de Perícia Criminal para fins de organização, tratamento e recuperação da informação para a elucidação de crimes.

\footnotetext{
3 Na Ciência da Informação, o conceito de objeto informacional é usado de forma ampla, englobando tradicionais tipos de recursos informacionais em bibliotecas e sistemas de informação, tais como livros, artigos de periódico, manuscritos, fotos, filmes, vídeos, dentre outros (HJØRLAND, 1997). São também denominados de materiais informacionais, recursos informacionais ou itens informacionais.

4 É um conjunto de procedimentos técnicos científicos aplicados em cenas criminais para se obter uma resposta, um esclarecimento sobre o crime.

${ }^{5} \mathrm{O}$ delito se constitui de uma infração as regras que foram estabelecidas pela sociedade.
} 
Diante do exposto, a presente pesquisa elucida, em linhas gerais, a importância do reconhecimento das competências e das atividades que podem ser desenvolvidas por esse profissional em outros cenários informacionais, transcendendo os espaços das bibliotecas, os quais são ambientes tradicionais de sua atuação.

Objetivando dar prosseguimento às reflexões apresentadas anteriormente, a seção a seguir discorre sobre as habilidades e competências do Bibliotecário, mediante uma revisão de literatura que evidencia as atividades biblioteconômicas que podem ser readequadas ao campo da perícia criminal.

\section{HABILIDADES E COMPETÊNCIAS DO BIBLIOTECÁRIO}

Como discute Fleury e Fleury (2001), competência é um termo que vem sendo debatido nos últimos anos, sendo associados às expressões como "[...] saber agir, mobilizar recursos, integrar saberes múltiplos e complexos, saber aprender, saber engajar-se, assumir responsabilidades, ter visão estratégica." Isto reflete no conjunto de conhecimentos adquiridos em diversas situações bem como habilidades e atitudes do próprio indivíduo.

Existe então uma tríade atrelada a esse termo conhecida como "CHA", que corresponde, respetivamente, a Conhecimentos, Habilidades e Atitudes que a pessoa possui (RABAGLIO, 2008). O primeiro termo diz respeito ao conjunto de conhecimentos técnicos, expertise que se apresenta como necessária para ocupar um cargo. A expressão "Habilidades", por sua vez, está atrelada às experiências e aptidões pessoais, ou seja, ao saber fazer do indivíduo; a possibilidade de conseguir colocar em prática o conhecimento científico que possui em conformidade com a realidade do ambiente em que atua, sabendo unir a teoria e a prática. De outro modo disposto, a expressão "Atitudes" é relativa ao comportamento humano, à iniciativa do profissional em fazer acontecer no ambiente que se encontra inserido. "O conhecimento corresponde a [...] dimensão do saber. A habilidade [...] ao saber-fazer [...]. Finalmente a atitude é a dimensão do querer-saber-fazer." (BARBALHO; ROZADOS, 2008, p. 3 , grifo dos autores).

Em síntese, o conjunto dessas dimensões vislumbra a necessidade do aprendizado contínuo ao longo da carreira, proporcionando o desempenho pleno das atividades que cada profissão deve cumprir.

As aptidões dos profissionais precisam ser aperfeiçoadas com novos estudos e novas práticas a fim de que eles atendam plenamente às demandas da sociedade, mantendo-se ativos e atuantes no mercado. Almeida Júnior (2002, p. 133) enfatiza que "O que o mercado procura atualmente é um profissional que tenha conhecimentos específicos, mas que os integre em concepções mais gerais que [...] ultrapassem o restrito espaço determinado pelo campo que escolheu [...]". Esses "conhecimentos específicos" estão diretamente relacionados às habilidades e competências profissionais.

Em seu artigo sobre perspectivas profissionais e educacionais dos bibliotecários, Barbosa (1998) discute como a denominação tradicional da profissão traz algumas desvantagens, uma vez que evidencia uma forte conexão do Bibliotecário com os livros e com a biblioteca. Além disso, "As escassas oportunidades [...] no mercado de trabalho refletem, em parte, a visão da sociedade a seu respeito e mesmo a visão que esses profissionais têm de si mesmos." (BARBOSA, 1998, p. 54). Dessa forma, a visão da sociedade e das organizações acerca dos bibliotecários pode estar atrelada à gestão de bibliotecas tradicionais, considerando que a maioria desconhece as competências dos mesmos para atuar em outros contextos informacionais. 
O conceito de informação é discutido por diversas áreas temáticas, as quais levam em consideração diferentes aspectos, haja vista a multiplicidade de perspectivas situadas na compreensão do fenômeno informacional, resultando em uma ausência de consenso quanto a sua definição. A informação, portanto, é derivada de várias fontes, não apenas daquelas que estão registradas na forma escrita e pode ser apresentada de variadas formas e de naturezas diversas. Diante disso, a seleção da informação mais relevante para a tomada de decisão passa a ser de responsabilidade do usuário e das instituições, em consonância com as suas necessidades informacionais. O profissional da informação, por sua vez, deve ser o responsável por promover o acesso à informação em todas as suas configurações e formatos.

A Ciência da Informação é uma das áreas temáticas cujas investigações estão centradas na informação cujo objetivo é "Investiga[r] as propriedades e o comportamento da informação, as forças que governam seu fluxo e os meios de processá-la para otimizar sua acessibilidade e uso." (BORKO, 1968, p. 3). Essa área se dedica ao "[...] corpo de conhecimentos relacionado à coleta, organização, armazenagem, recuperação, interpretação, transmissão, transformação e utilização da informação [...]" (BORKO, 1968, p. 3), que resulta no delineamento de ações investigativas técnicas e científicas dessa área do conhecimento como campo científico.

Dada a complexidade do objeto de estudo da Ciência da Informação (a informação) e a multiplicidade de perspectivas situadas na compreensão do fenômeno informacional em todos os campos do conhecimento humano, o pluralismo epistemológico e a natureza interdisciplinar dessa área do conhecimento torna-se evidente (SANTOS; NEVES; SOUZA, 2019). Nesse segmento, os processos de organização e tratamento da informação realizados por profissionais da área são cruciais para pensar a recuperação, o acesso e o uso da informação em diferentes contextos.

A Classificação Brasileira de Ocupações (CBO), documento que reconhece e "[...] descreve as características das ocupações do mercado de trabalho brasileiro [...]" (BRASIL, 2008a), considera e classifica o Bibliotecário, o Documentalista e o Analista de informações na categoria dos Profissionais da Informação apresentando as seguintes atividades que podem ser exercidas por esses profissionais:

\footnotetext{
Disponibilizar informação em qualquer suporte; gerenciar unidades como bibliotecas, centros de documentação, centros de informação e correlatos, além de redes e sistemas de informação. Tratar tecnicamente e desenvolver recursos informacionais; disseminar informação com o objetivo de facilitar o acesso e geração do conhecimento; desenvolver estudos e pesquisas; realizar difusão cultural; desenvolvem ações educativas. Podem também prestar serviços de assessoria e consultoria. (BRASIL, 2008a).
}

Esse documento, além de definir as ocupações do mercado brasileiro, apresenta uma lista de atividades desempenhadas pela função escolhida. No caso do Bibliotecário, a CBO aponta atividades divididas em dez categorias gerais, a saber: 1) Disponibilizar informação em qualquer suporte; 2) Gerenciamento de unidades, redes e sistemas de informação; 3) Tratamento técnico dos recursos informacionais; 4) Desenvolvimento dos recursos informacionais; 5) Disseminação da Informação; 6) Desenvolvimento de Estudos e Pesquisas; 7) Prestação de serviços de Assessoria e Consultoria; 8) Promoção de atividades de Difusão Cultural; 9) Desenvolvimento de ações educativas; 10) Demonstração de competências pessoais. 
Outro aspecto importante a ser observado na CBO é que, no âmbito da última classificação, a qual é denominada de "Demonstração de Competências pessoais", são delineadas atividades que se constituem como competências e que devem ser aplicadas no desenvolvimento de todos os exercícios elencados anteriormente, sem que o seu desempenho seja considerado isoladamente em uma classificação. Portanto, tais competências devem ser consideradas pelo Bibliotecário em todos os cenários de sua atuação.

Faria et al. (2005), Rasteli e Cavalcante (2013), e Ottonicar, Basseto e Feres (2015) ressaltam que esse profissional deve manter-se atualizado, trabalhar em equipes, conhecer outros idiomas, ter capacidade empreendedora, ser proativo e buscar a ética como princípio.

Em linhas gerais, é possível perceber que essas competências possuem correlação com o que está descrito na Lei no 4.084/62, a qual dispõe sobre o exercício da profissão. Verifica-se ainda que os conhecimentos relativos às atividades supracitadas são adquiridos na graduação e no fazer da profissão. Sendo assim, enquanto a lei permeia atribuições gerais, a CBO a complementa delineando características e funções específicas ao cargo.

Portanto, para que o bibliotecário possa desempenhar atividades em unidades de informação e sistemas de recuperação da informação em diferentes instituições, as suas competências (conhecimentos, habilidades e atitudes) necessitam romper paradigmas para conquistar novos cenários de atuação, sobretudo, em tempos de pós-verdade e de alta incidência de fake news. A capacidade de esse profissional identificar, recuperar, analisar e utilizar adequadamente materiais informacionais e ferramentas analíticas para identificação de diferentes tipos de fakes e robôs torna-se cada vez mais necessária no hodierno contexto.

Uma área de estudo que pode desenvolver investigações interdisciplinares com a Ciência da Informação é a perícia criminal. As atividades desempenhadas por profissionais da informação podem apresentar contribuições impreteríveis para essa área do conhecimento, dada a complexidade e o advento de novos suportes, processos, tecnologias que auxiliam as práticas forenses e o acesso às informações confiáveis que demonstram a integridade dos fatos ocorridos e registrados.

\section{3 ÓRGÃOS OFICIAIS DE PERÍCIA CRIMINAL: FUNÇÕES E OBJETIVOS}

Uma das organizações que pode se beneficiar das competências dos profissionais da informação são as instituições criminalísticas, ou seja, os órgãos oficiais de perícia criminal. Portanto, se faz necessário estudar as funções e os objetivos dessas instituições, bem como aspectos concernentes ao seu desenvolvimento na sociedade.

A segurança é uma das questões mais importantes no desenvolvimento da sociedade. Os meios sociais promulgam leis e regras para reger a sociedade garantindo a liberdade e a preservação da integridade de todos os cidadãos. O problema da insegurança ameaça um direito fundamental previsto na Constituição da República Federativa: a segurança pública. $O$ Estado e aquela que the permite o poder, isto é, a sociedade, tornam-se responsáveis por combater a violência/criminalidade, preservando a ordem e a integridade de todos que fazem parte da comunidade.

Para tanto, são elaboradas políticas públicas, as quais se configuram como um conjunto de ações do Estado que visa à participação de entidades públicas ou privadas, assegurando determinados direitos aos cidadãos. Dessa maneira, a existência dos órgãos de perícia oficial de natureza criminal permite revelar os autores dos crimes e quem perturba a harmonia social, para que o Sistema de Justiça Criminal tome as devidas providências (LIMA, 2012). 
Os órgãos que integram o Sistema de Justiça Criminal vão desde os responsáveis pela Segurança Pública, Ministério Público e o Poder Judiciário. Dentre os órgãos de segurança pública, estão Polícia Federal, Polícia Rodoviária Federal, Polícia Ferroviária Federal, Polícia Civil, Polícia Militar, Corpo de Bombeiros e todos os outros responsáveis pela defesa civil. Lima $(2012$, p. 34) ainda acrescenta "[...] o Instituto Nacional de Criminalística da Polícia Federal e os Institutos de Criminalística e Institutos Médico-Legais dos Estados e Distrito Federal, responsáveis pela prova pericial de natureza criminal, indispensável nos crimes que deixam vestígio.". Dessa forma, observa-se que todos os órgãos precisam agir de maneira coerente e integrada para atender aos interesses da sociedade no intuito de garantir o direito à segurança pública.

Esses órgãos trabalham com a informação para fins de elucidação de crimes e são "[...] responsáveis pela constatação da materialidade e da autoria dos fatos criminosos, principalmente no que tange à confiabilidade e certeza da prova por eles produzida." (CUNHA, 2012 , p. 14). Para tanto, tem como principal serviço a perícia criminal. Essa atividade é desenvolvida para garantir a integridade e a liberdade do cidadão, previstas no artigo 5o da Constituição Federal (BRASIL, 2020), uma vez que as investigações em cima dessas provas criminais contribuem em defesa dos direitos humanos.

A perícia criminal consiste na investigação de delitos a partir de evidências deixadas no local. Essa investigação é realizada por um especialista a fim de obter conclusões pertinentes ao caso em questão ( $\mathrm{NUCCl}, 2012)$. Nesse segmento, vestígios como resíduos balísticos, mancha de sangue e pegadas são provas materiais de determinado evento e servem como fontes de informação para a elucidação de crimes. Esses vestígios possuem naturezas diversas, sendo essencial o conhecimento das áreas das ciências naturais como Biologia e Química, bem como de áreas complementares como Informática, Engenharia, por exemplo.

De acordo com o Código de Processo Penal (CPP), "[...] Quando a infração deixar vestígios [...]" (BRASIL, 2019), "[...] O exame de corpo de delito ${ }^{6}$ e outras perícias serão realizados por perito oficial, portador de diploma de curso superior." (BRASIL, 2008c). Com o resultado da análise técnico-científica dos materiais coletados na cena do crime, o profissional produz um laudo pericial que corresponde às observações feitas durante todo o processo investigativo, que podem averiguar e comprovar a inocência ou condenação do(s) culpado(s).

Segundo Lima (2012, p. 23), "[...] a investigação realizada pelo Perito Oficial é científica, baseada, única e exclusivamente, no levantamento de provas materiais, por meio de técnicas forenses [...]". Sob esse viés, o perito, com diploma superior, verifica a cena do crime colhendo provas materiais, inclusive material fotográfico para a construção dos seus laudos periciais. Nesse entendimento,

Perito é "aquele que é experimentado ou prático em determinado assunto".

O Perito Oficial de Natureza Criminal pode ser tanto o Perito Criminal, como o Perito Médico Legista; e é o profissional, aprovado em concurso público de provas e títulos, responsável pela realização da Perícia Oficial Brasileira de Natureza Criminal, entendimento do art. 159, do Código de Processo Penal [...]. (AMORAS, 2008, p. 537 apud LIMA, 2012, p. 23, grifo nosso)

Com isso, percebe-se que os profissionais peritos criminais são servidores públicos cujas formações podem ser oriundas de diversas áreas do conhecimento, como, por exem-

\footnotetext{
${ }^{6}$ Exame de corpo de delito é a análise de provas da existência do crime "[...] sendo que a sua falta provocará a nulidade do processo, conforme o art. 564, III, b, do Código de Processo Penal." (LIMA, 2012, p. 37).
} 
plo, Medicina, Física, Farmácia, Engenharia, Química, etc. Após a sua aprovação em concurso público destinado para a habilitação do exercício da função, os seus títulos são averiguados de acordo com o edital do certame e, posteriormente, tais profissionais são finalmente nomeados pelo Estado.

No intuito de correlacionar as atividades desempenhadas pelos peritos criminais que possuem relação com as competências e habilidades do Bibliotecário, buscou-se apresentar a descrição dos peritos criminais conforme definido na CBO, bem como as atividades que competem a esse cargo. Dessa forma, nas condições gerais associadas ao exercício dos peritos criminais são apresentadas as seguintes descrições:

\begin{abstract}
Esses profissionais atuam nas áreas ligadas à administração pública, defesa e seguridade social. São assalariados e se organizam em equipe. Trabalham com supervisão ocasional, em ambiente fechado, a céu aberto e em veículos. Seus horários de trabalho são variados. Podem ficar longos períodos em posições desconfortáveis, trabalhar sob pressão, (levando-os a situação de estresse constante) e expostos a materiais tóxicos, radiação e ruído intenso (BRASIL, 2008b).
\end{abstract}

Com base nessa perspectiva, verifica-se que as atividades de responsabilidade desses profissionais são divididas em nove classes gerais, a saber: 1) Elaborar laudo pericial; 2) Examinar locais de crime; 3) Analisar peças e materiais relacionados a crime; 4) Realizar ensaios; 5) Efetuar medições; 6) Atender requisição; 7) Organizar o trabalho; 8) Desenvolver métodos e técnicas científicos; 9) Demonstrar competências pessoais.

É possível perceber uma série de práticas que necessitam de habilidades e competências para o desempenho de atividades específicas, dentre elas: realização de ensaios toxicológicos, ensaios de sangue, realizações de medições físico-químicas, cálculos matemáticos, entre outros. Em função dessas atividades, Graduações como Geologia, Engenharia Química, Engenharia Eletrônica, Informática, Biomedicina, Engenharia Florestal, Medicina, Odontologia, Farmácia, e Física, entre outras, são algumas das exigidas para atuar como Perito Criminal (ASSOCIAÇÃO..., 2017).

De acordo com Rodrigues, Silva e Truzzi (2010), o laudo pericial também consiste em um material informacional importante para os promotores de justiça e juízes de Direito, haja vista que esses profissionais necessitam da sua construção para fins do arquivamento do inquérito policial ou fornecimento de denúncia contra alguém, levando em conta que essa última ação depende da prova de que o crime existiu (materialidade) com indícios de autoria.

Essa espécie documental contribui efetivamente para o desempenho das atividades não somente realizadas pelos profissionais que atuam nessas instituições, mas também para os usuários considerados destinatários externos do serviço, como, por exemplo, os promotores de justiça e os juízes de Direito. Esses profissionais são de instituição externa e precisam de informações estruturadas para aplicar a lei ao caso concreto.

É importante apresentar também nesta pesquisa os usuários beneficiários da perícia, ou seja, aquelas pessoas que, de alguma forma, se beneficiam dos serviços desempenhados pelos Órgãos Oficiais de Perícia Criminal. Rodrigues, Silva e Truzzi (2010) mencionam:

- A sociedade como um todo: apresenta interesse em uma justiça criminal que encontre e puna os responsáveis pelos delitos cometidos, ou inocentes aquelas pessoas erroneamente acusadas, respeitando os direitos humanos.

- A Polícia e a Justiça Criminal: necessitam dos serviços desempenhados para identificar e julgar os verdadeiros autores dos delitos, necessitando que a perícia con- 
tribua para este anseio da sociedade com provas científicas que auxiliem na elucidação de crimes.

- As vítimas e/ou os seus familiares: necessitam deste trabalho para fins de esclarecimento dos fatos.

- Os suspeitos: são usuários beneficiários da perícia, na medida em que não é necessário constrangê-los durante as investigações.

- Os advogados de defesa: utilizam as informações da perícia para formular as estratégias de defesa dos seus clientes.

- As testemunhas: fazem uso, na medida em que a perícia auxilia na confirmação ou refutação dos depoimentos.

- A mídia: faz uso para fins de repercussão/disseminação dos casos dando-lhes uma maior ou menos dimensão. Além disso, necessita informar a opinião pública com maior precisão.

- As Organizações de Direitos Humanos: utilizam os laudos periciais para fins de avaliação das ações periciais, por exemplo.

Em síntese, a Figura 1 apresenta os principais públicos da Perícia Criminal.

Figura 1 - A Perícia Criminal e os seus principais públicos

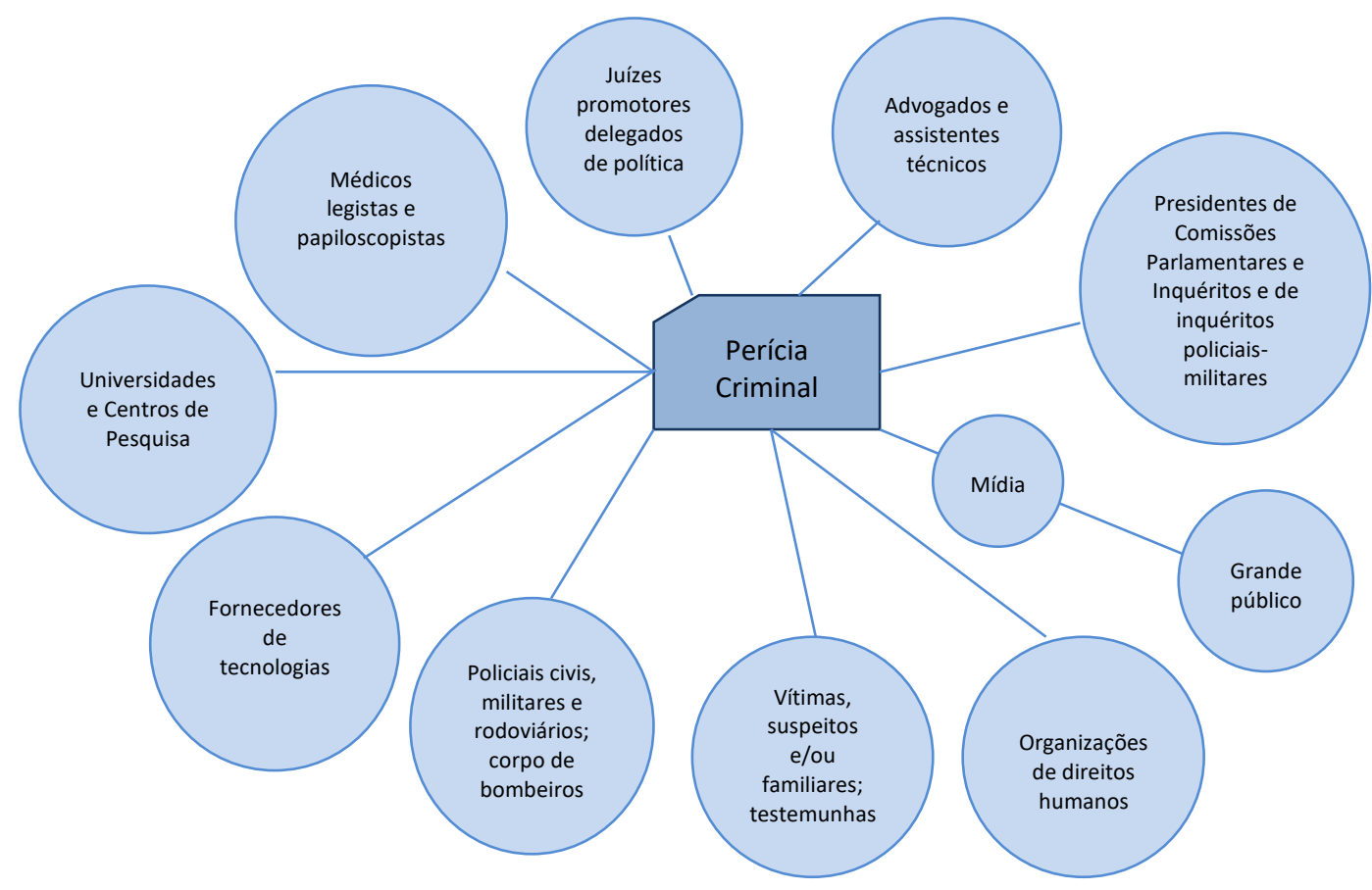

Fonte: Rodrigues, Silva e Truzzi (2010, p. 848).

Diante disso, é fundamental investigar e identificar os destinatários/usuários de qualquer serviço para fins de estabelecimento da relação entre o prestador, nesse caso o perito criminal, e os destinatários a fim de desempenhar atividades que contribuam significativamente para a satisfação das suas necessidades informacionais. 


\subsection{Cadeia de custódia de vestígios}

Durante a pesquisa sobre os Órgãos Oficiais de Pericia Criminal, foi identificado que existe um conjunto de procedimentos que leva o nome de Cadeia de Custódia de Vestígios (CCV), os quais possuem como premissa a guarda, a preservação da evidência para a realização de todas as análises até o descarte da prova. No que diz respeito à acepção do termo "Cadeia", este pode somar a dois significados: o primeiro está associado ao conceito de prisão, presídio ou reclusão; e o segundo significado está associado a um fluxo de processos. Entretanto, é importante destacar que a denominação CCV nesta pesquisa está associada ao fluxo/guarda/preservação dos vestígios. Esse processo possui funções que se assemelham, de certo modo, às atividades desempenhadas no âmbito das unidades de informação.

Portanto, "[...] Denomina-se cadeia de custódia o conjunto de todos os procedimentos utilizados para manter e documentar a história cronológica do vestígio, para rastrear sua posse e manuseio a partir de seu reconhecimento até o descarte." (BRASIL, 2014).

Trata-se então de um conjunto de medidas administrativas a serem adotadas pelos Órgãos de Polícia Judiciária para acompanhar e registrar todos os eventos e movimentações a que é submetida a prova material produzida, com a finalidade de impingir-lhe idoneidade jurídica [...].

Os procedimentos de custódia hoje adotados em alguns órgãos de perícia, são frutos de ações isoladas, e visam apenas resguardar a idoneidade de vestígios de origem orgânica, bem como substâncias diversas a serem examinadas em laboratório. Entretanto, tal qual ocorre no âmbito do Distrito Federal, observa-se que outros tipos de vestígios vinculados a novas modalidades de delitos criminais, tais como hardwares, fotografias, softwares, impressões digitais e grande variedade de mídias e equipamentos audiovisuais merecem procedimentos específicos de CC [Cadeia de Custódia] para a manutenção de sua relevância probatória. (CUNHA, 2012, p. 15).

Nessa perspectiva, verifica-se que as atividades a serem desempenhadas em uma CCV começam quando a primeira evidência é encontrada e todos os envolvidos que os manusearam para algum fim precisam prezar pela cadeia, pois seu término ocorre apenas com o fim do processo criminal. Percebe-se que existe uma preocupação em manter os vestígios de qualquer natureza para salvaguarda do material garantindo a sua integridade para fins de realização de novos exames, caso necessário. Sendo assim, as evidências passam por uma série de procedimentos que precisam ser registrados, garantindo a confiabilidade.

Marinho $(2014$, p. 12) manifesta

[...] a necessidade de uma central de custódia destinada à guarda e ao controle dos vestígios de modo a garantir a integridade e a idoneidade do material que serviu de base para o exame realizado pelo perito oficial e atender o dispositivo no $\S 6$ do art. 159 do Código de Processo Penal.

Deste modo, qualquer desconfiança que surgir no mundo jurídico quanto à garantia da autenticidade e/ou da idoneidade poderá ser esclarecido por meio do rastreamento do processo.

O parágrafo a que se refere o autor, diz respeito à guarda do material em função de haver requerimento das partes do material probatório (BRASIL, 2008c).

A Portaria $\mathrm{n}$ - 82, de 16 de junho de 2014, ainda destaca que:

4.2. Na central de custódia, a entrada e a saída de vestígio deverá ser protocolada, consignando-se informações sobre a ocorrência/inquérito que a eles se relacionam. 
4.3. Todas as pessoas que tiverem acesso ao vestígio armazenado deverão ser identificadas e deverá ser registrada data e hora do acesso.

4.4. Quando da tramitação do vestígio armazenado, todas as ações deverão ser registradas, consignando-se a identificação do responsável pela tramitação, destinação, data e horário da ação.

4.5. O procedimento relacionado ao registro deverá:

a) ser informatizado ou através de protocolos manuais sem rasuras;

b) permitir rastreamento do objeto/vestígio (onde e com quem se encontra) e a emissão de relatórios;

c) permitir a consignação de sinais de violação, bem como descrevê-los;

d) permitir a identificação do ponto de rompimento da cadeia de custódia com a devida justificativa (responsabilização);

e) receber tratamento de proteção que não permita a alteração dos registros anteriormente efetuados, se informatizado. As alterações por erro devem ser editadas e justificadas;

f) permitir a realização de auditorias. (BRAISL, 2014).

As práticas mencionadas anteriormente também podem ser beneficiadas com a atuação dos profissionais bibliotecários, como, por exemplo, no âmbito de uma central de custódia, uma vez que os vestígios se configuram como objetos informacionais que devem ser organizados e tratados para fins de sua recuperação. Os ofícios da Perícia Criminal dependem essencialmente da interdisciplinaridade entre as disciplinas do conhecimento humano, assim acredita-se que é possível agregar os valores e as práticas oriundas de mais uma ciência: a Ciência da Informação, em especial as atividades inerentes à Biblioteconomia.

Esta seção partiu de um olhar sobre a perícia a partir das produções científicas sobre o tema e das atividades exercidas em Órgãos Oficiais de Perícia Criminal, levando em conta o trabalho técnico-científico necessário para fins de elucidação de crimes. Com base nesse entendimento, a Figura 2 apresenta as atividades que podem ser desempenhadas pelo profissional da informação no trabalho com os peritos criminais, com base nas informações extraídas da CBO do Bibliotecário e nas informações coletadas em entrevista semiestruturada realizada com sujeitos que atuam no campo da perícia criminal.

Figura 2 - Atividades que o Bibliotecário pode desempenhar em Órgãos Oficiais de Perícia Criminal

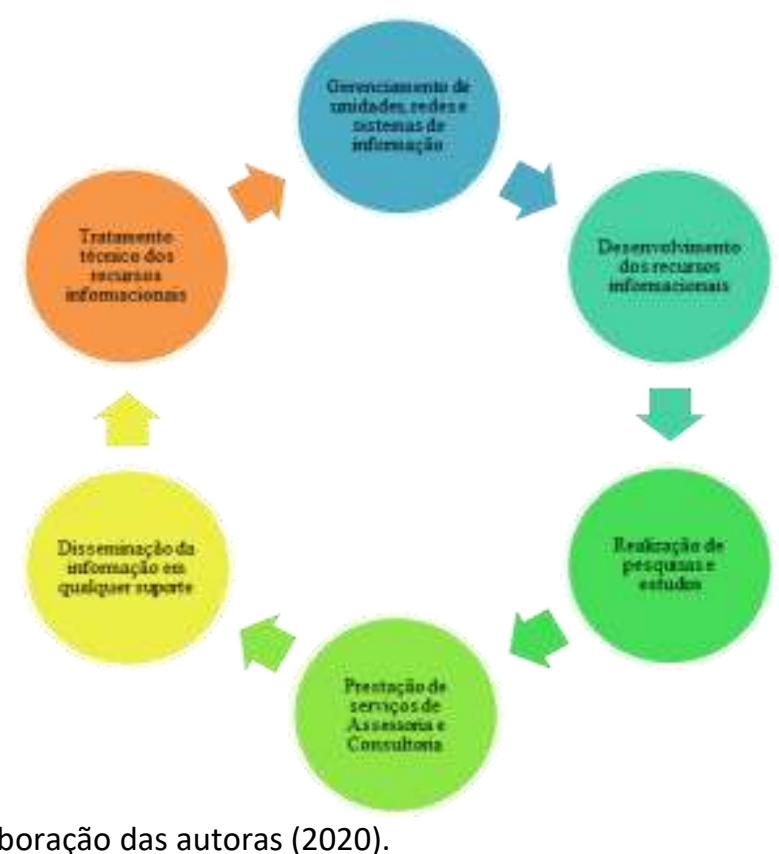

Fonte: Elaboração das autoras (2020). 
Portanto, dentre as dez classificações destacadas pela CBO do Bibliotecário, seis delas apresentam atividades que podem ser desempenhadas/aperfeiçoadas/aplicadas em Órgãos Oficiais de Pericia Criminal visando contribuir significativamente para o desempenho de serviços nesse contexto. Configuram-se como foco deste artigo as atividades de organização, tratamento e recuperação da informação, práticas que condicionam o acesso e uso da informação. Essas atividades estão vinculadas às seguintes classes: a) gerenciamento de unidades, redes e sistemas de informação; b) tratamento técnico de recursos informacionais.

A seguir são apresentados os procedimentos metodológicos empreendidos para a realização desta pesquisa.

\section{PERCURSO METODOLÓGICO}

Quanto aos seus objetivos e à obtenção de informações, este estudo caracteriza-se como pesquisa bibliográfica e documental com abordagem exploratório-descritiva a partir de dados extraídos da CBO do Perito Criminal e do Bibliotecário, bem como da aplicação de entrevista semiestruturada a profissionais que atuam na Perícia Criminal.

No que concerne à obtenção de informações, este estudo é de natureza bibliográfica, uma vez que foram pesquisadas, analisadas e avaliadas questões sobre as habilidades e competências do profissional da informação, bem como sobre a perícia criminal em fontes de informação como teses, dissertações e artigos em formatos impresso e eletrônico. Essas produções científicas contribuíram para o desenvolvimento da fundamentação teórica sobre o tema, além de permitir o desenvolvimento de questões e reflexões referentes à área de Biblioteconomia e Ciência da Informação.

Esta pesquisa também é de natureza exploratória, uma vez que foi possível explorar questões concernentes às práticas e aos conceitos associados ao profissional da informação e à perícia criminal nas produções científicas e nas leis, no intuito de desenvolver os fundamentos teóricos e as análises deste estudo.

Ainda no que concerne à obtenção de informações, este estudo é classificado como uma pesquisa documental, haja vista que foi realizada a coleta de informações em documentos legais, como as leis que regem as profissões do Bibliotecário e do Perito Criminal, a CBO de ambas as profissões, o Sistema formado pelo Conselho Federal de Biblioteconomia e pelos Conselhos Regionais de Biblioteconomia (Sistema CFB/CRB) e o Código de Processo Penal.

Os conteúdos dessas fontes de informação se configuraram como matéria-prima a partir da qual foram desenvolvidas as investigações e análises presentes nesta pesquisa. Outrossim, este estudo possui natureza descritiva, uma vez que foi realizada a descrição do campo da Perícia Criminal e das possíveis atuações do profissional Bibliotecário em tal cenário, bem como foi aplicada uma entrevista semiestruturada para fins de descrição do posicionamento dos sujeitos acerca das reflexões apontadas neste estudo.

Desse modo, foi elaborado um conjunto de questões pré-definidas em roteiro de entrevista que se constituíram como "guia" para a aplicação da entrevista semiestruturada com dois profissionais que atuam no campo da Perícia Criminal (um Perito Criminal e um agente da Política Civil). Os questionamentos apresentados a esses sujeitos contemplavam aspectos relativos aos Órgãos Oficiais de Perícia Criminal, às atividades desempenhadas nesses órgãos, bem como às habilidades e competências do Bibliotecário para atuar nesse campo. É importante ressaltar que os nomes dos sujeitos, dados e especificação do cargo nas instituições em que fazem parte foram preservados, tendo em vista a ética na pesquisa. 
Com a entrevista semiestruturada foi possível acrescentar outros questionamentos não contemplados no roteiro da entrevista. Essa atividade possibilitou esclarecer algumas dúvidas com os entrevistados/informantes visando tornar a coleta dos dados mais exaustiva, bem como enriquecer o referencial teórico, as análises e os resultados deste estudo que possui abordagem qualitativa.

As etapas da pesquisa são apresentadas na Figura 3 a seguir.

Figura 3 - Etapas da pesquisa

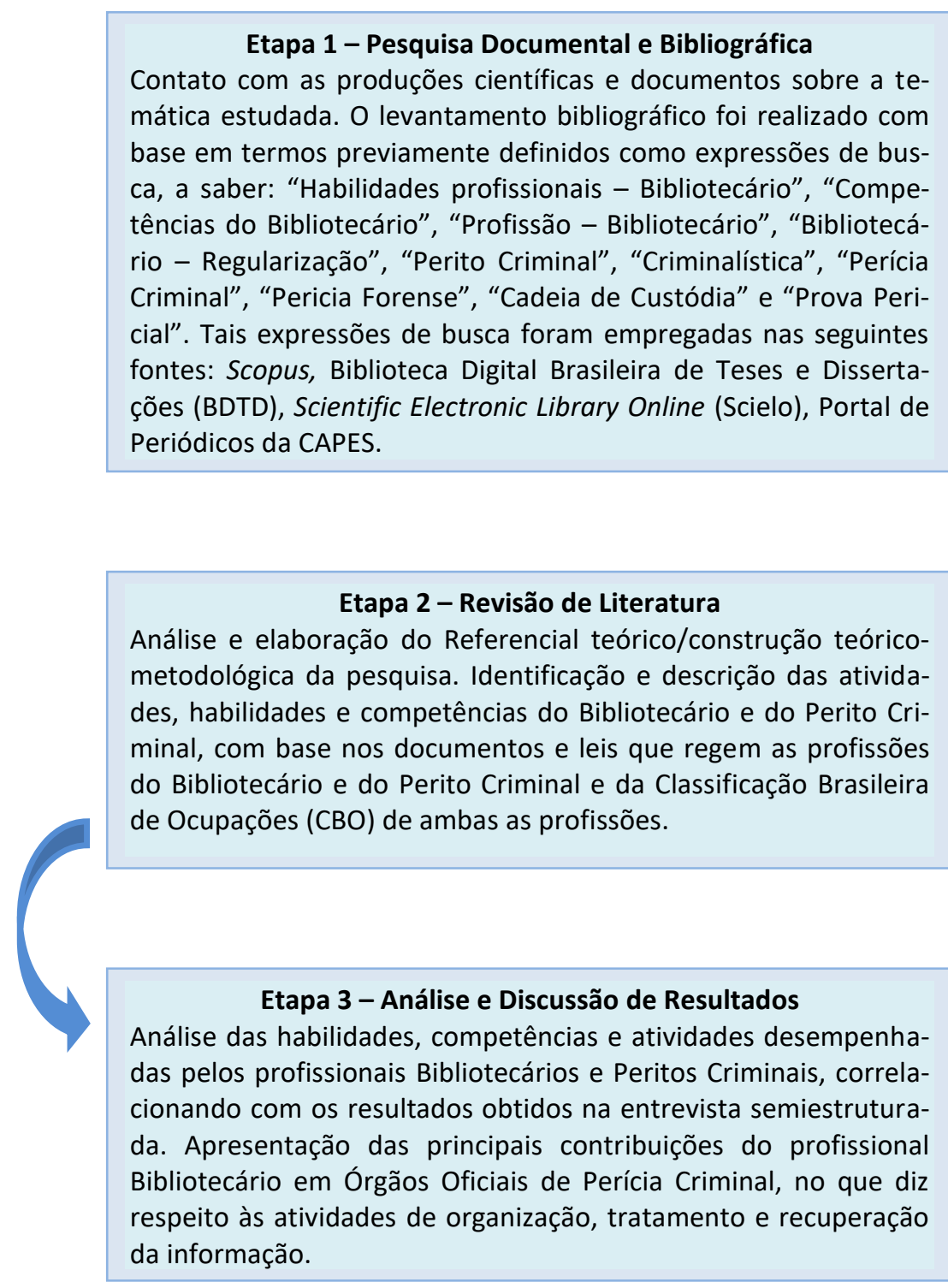

Fonte: Elaboração das autoras (2020).

Na seção a seguir, são apontadas as principais atividades que podem ser desenvolvidas pelo profissional Bibliotecário em Órgãos Oficiais de Perícia Criminal, levando em consideração as suas habilidades e competências enquanto profissional da informação, bem como os objetivos e funções das instituições supracitadas. 


\section{ORGANIZAÇÃO E TRATAMENTO DA INFORMAÇÃO EM ÓRGÃOS OFICIAIS DE PERÍCIA CRIMINAL}

Inicialmente foram analisadas as atividades descritas na CBO do Bibliotecário como ponto de referência. Em seguida, foram identificadas e selecionadas aquelas que podem atender às competências gerais exigidas nessa profissão, especificamente, no que concerne às práticas de organização, tratamento e recuperação da informação. Portanto, as atividades selecionadas se constituem como um conjunto de serviços que podem ser desenvolvidos nessas instituições criminalísticas.

Das seis classificações apresentadas na terceira seção deste artigo, sintetizadas na Figura 2, observou-se que duas delas são evidenciadas no quadro de atividades que podem ser desenvolvidas pelo Bibliotecário em Órgãos Oficiais de Perícia Criminal, são elas: a) Gerenciamento de unidades, redes e sistemas de informação; b) Tratamento técnico dos recursos informacionais. Essas atividades possuem relações entre si e contribuem para os processos de gerenciamento, organização, tratamento e recuperação da informação nessas instituições, razão pela qual foram selecionadas nesta pesquisa.

A primeira classe de atividades extraídas da CBO do Bibliotecário refere-se ao Gerenciamento de Unidades, Redes e Sistemas de Informações, cujas atividades são elencadas na Figura 4.

Figura 4 - Atividades associadas ao Gerenciamento de Unidades, Redes e Sistemas de Informação

\begin{tabular}{l} 
Elaborar programa e projetos de ação \\
Administrar o compartilhamento de recursos informacionais \\
Desenvolver políticas de informação \\
Automatizar unidades \\
Controlar a execução de planos de atividades \\
\hline Avaliar serviços e produtos \\
\hline Elaborar relatórios, manuais de serviços e procedimentos \\
Implementar redes, sistemas e unidades de informação \\
Analisar tecnologias de informação e comunicação \\
\hline
\end{tabular}

Fonte: Elaboração das autoras (2020).

Nesse entendimento, percebe-se que as atividades dessa área possuem uma relação direta com o gerenciamento de um local de guarda dos vestígios. No que diz respeito aos aspectos de gerenciamento, as unidades fazem uso de recursos para a manutenção dos seus serviços. No âmbito de uma central onde ficam os vestígios, faz-se necessária a atuação de um profissional que seja capaz de perceber as nuances desse ambiente no que se refere aos recursos informacionais, tecnológicos, financeiros e de pessoal a fim de manter a preservação, a integridade e o sigilo dos diversos materiais informacionais que podem circular nesse contexto.

Nessa perspectiva, toda a administração precisa ser pensada para atingir os objetivos desejados. O profissional precisa acompanhar ou planejar a unidade de informação; desenvolver políticas para o seu funcionamento; compreender os melhores recursos tecnológicos que atendam às demandas do dia a dia e dos usuários especializados; criar padrões de qualidade para reconhecimento da instituição mantenedora e dos outros profissionais da instituição (nesse caso os peritos, os agentes de investigação, por exemplo). 
Em relação aos serviços e produtos, o Bibliotecário deve estar sempre atento à avaliação e ao controle, aprimorando-os quando for necessário. Nesse entendimento, vale destacar a importância do compromisso desse profissional com a estrutura patrimonial e com as provas que estão armazenadas enquanto materiais informacionais.

Em síntese, o bom funcionamento das atividades associadas ao gerenciamento de unidades, redes e sistemas de informação também vai depender da construção de relatórios, políticas e manuais de serviços visando à padronização e ao desenvolvimento das tarefas por novos e antigos funcionários. Diante do exposto, verifica-se que essa classe, assim como as demais, possui elementos importantes do perfil gestor a ser desenvolvido pelo profissional da informação nesses órgãos.

A segunda classe de atividades que podem ser evidenciadas como propostas de serviços a serem desempenhados pelo profissional nessas instituições diz respeito ao Tratamento Técnico dos Recursos Informacionais, cujas atividades estão diretamente vinculadas à organização, ao tratamento e à recuperação da informação e são apresentadas na Figura 5.

Figura 5 - Atividades associadas ao Tratamento Técnico dos Recursos Informacionais

Registrar recursos informacionais
Classificar e indexar recursos informacionais
Catalogar recursos informacionais
Elaborar sistemas de Organização do Conhecimento (SOCs)
Desenvolver bases de dados
Gerar fontes de informação

Fonte: Elaboração das autoras (2020).

Concomitante com a área anterior, o profissional da informação pode fazer uso de seus conhecimentos de representação para registrar, catalogar, classificar e indexar os vestígios utilizados pelos peritos, garantindo um acesso eficiente e eficaz. A catalogação e indexação de vestígios como softwares, impressões digitais, fotografias, áudios, imagens em movimento (vídeos, por exemplo) e das peças materiais pode ser uma atividade de extrema importância a ser desempenhada por esse profissional no intuito de contribuir para a elucidação de crimes, bem como para a qualidade da precisão e da revocação ${ }^{7}$ em sistemas de recuperação nos Órgãos Oficiais de Perícia Criminal.

Além disso, mediante o apoio dos demais profissionais, o Bibliotecário pode elaborar Sistemas de Organização do Conhecimento/sistemas conceituais (ontologias, taxonomias, tesauros, por exemplo), no contexto da perícia criminal, visando auxiliar nos processos de busca e recuperação da informação para a elucidação de crimes e suas tipologias. Também se faz necessário o desenvolvimento de sistemas e bases de dados na perspectiva de elaborar mecanismos e estratégias de busca e recuperação da informação, de indexação de documentos, por exemplo.

Cabe registrar que na entrevista realizada, os sujeitos da pesquisa apontaram a importância de o profissional da informação trabalhar no tratamento técnico desses recursos no âmbito das instituições criminalísticas, uma vez que não há um acervo organizado para a conservação e preservação das provas encontradas.

\footnotetext{
${ }^{7}$ De acordo com Santos (2016), precisão e revocação são medidas relativas à probabilidade dos documentos recuperados serem compatíveis com aquilo que os usuários estão buscando em um sistema de informação.
} 
Diante disso, destaca-se a necessidade da classificação dessas provas, bem como um ordenamento lógico a ser desenvolvido para facilitar a recuperação dos materiais, como por exemplo: por temática (crimes contra a vida, crimes contra o patrimônio, acidentes de trânsito, engenharia e meio ambiente); por exames especializados (áudios, vídeos, imagens, etc.); e por exames laboratoriais (química, física, biologia, bacteriologia, balística, toxicologia).

Complementando tais ideias, um dos entrevistados afirmou ainda que o Bibliotecário seria muito importante para a organização do centro de documentação e do cartório dessas instituições, pensando na possibilidade de o mesmo lidar com o processo cartorário de todos os crimes e na grande quantidade de processos e inquéritos existentes nesse contexto.

Destacou-se, ainda, que o profissional da informação pode atuar na organização da CCV. Contudo, destaca-se a necessidade de o Bibliotecário também adquirir conhecimentos essenciais de disciplinas naturais (como por exemplo, Química, Biologia e Física) em formação complementar, uma vez que os vestígios possuem diversas naturezas e que cabe ao profissional atentar para essas características visando garantir a transparência da produção da prova pericial: da matéria-prima (vestígio) até o produto acabado (prova pericial). Contudo, acreditando que os profissionais ainda poderão passar por capacitações, especializações com vistas a uma educação continuada em outros cursos profissionalizantes, após a sua aprovação para atuar nesses órgãos, foi ressaltado que esse profissional tem grandes chances de se mostrar atuante e apresentar o seu diferencial nesses novos cenários.

Quando questionados sobre essas Centrais de Custódia, os sujeitos entrevistados afirmaram que Brasília e Rio Grande do Sul possuem essas unidades e que os profissionais que trabalham nesses ambientes são Médicos Legistas e Peritos Criminais. Diante disso, os sujeitos ressaltaram a necessidade de um Bibliotecário para desempenhar serviços na área de organização das provas periciais em espaços físicos e/ou sistemas automatizados.

Em linhas gerais, percebe-se que uma quantidade significativa de atividades a serem desempenhadas por profissionais Bibliotecários em Órgãos Oficiais de Perícia Criminal estão relacionadas com o fazer desse profissional em unidades de informação, sobretudo, no que concerne à sua atuação na Central de Custódia, atendendo a requisito que a mesma propõe. A equipe da central gerida, ou até mesmo acompanhada por um profissional da informação, pode desenvolver produtos e serviços que atendam às demandas dos órgãos assegurando o sucesso das práticas dos peritos criminais.

Em linhas gerais, o Bibliotecário deve analisar e identificar as potencialidades informativas em cada tipologia de vestígio a ser organizado, representado e recuperado no âmbito dos órgãos oficiais de perícia criminal, considerando a diversidade dos seus usuários reais e potenciais citados anteriormente. Nesse sentido, a área da perícia criminal possui múltiplas perspectivas e linhas de pesquisa que podem ser beneficiadas com as habilidades do profissional da informação.

Por conseguinte, constatou-se que existe uma demanda de recursos humanos com certas habilidades e que dentro dos órgãos supracitados há um aprimoramento de determinadas funções com o decorrer do tempo, sendo necessário um aperfeiçoamento dos seus profissionais em outras ciências no intuito de formar recursos humanos especializados em áreas como documentoscopia, balística, meio ambiente, entre outros.

As atividades que lidam diretamente com a manipulação de vestígios que requeiram conhecimentos essenciais de disciplinas naturais como, por exemplo, Química e Biologia não são de competências do profissional da informação. No que consta à realização de perícias, o Bibliotecário pode contribuir para a realização das análises dos documentos com base nos 
conhecimentos biblioteconômicos adquiridos na sua graduação e já expostos anteriormente. Entretanto, de acordo com as informações extraídas da entrevista semiestruturada, verificou-se que, após a especialização desse profissional em conhecimentos de outras áreas, o mesmo pode avaliar também os vestígios criminais, podendo contribuir para a obtenção das respostas para os crimes.

Os Bibliotecários necessitam romper paradigmas para conquistar novos cenários de atuação, sobretudo, em tempos de pós-verdade e de alta incidência de fake news. Esses profissionais devem saber identificar, recuperar, analisar e utilizar adequadamente materiais informacionais e ferramentas analíticas para identificação de diferentes tipos de fakes e robôs que dificultam a identificação e a recuperação de vestígios no campo da perícia criminal.

As competências pessoais também são essenciais à realização de qualquer atividade desse profissional. Nesse sentido, a manutenção do seu equilíbrio e da sua inteligência emocional é de extrema importância em instituições criminalísticas, sobretudo nas práticas de organização, tratamento e recuperação da informação.

As fases do processo de indexação, por exemplo, sofrem influências de fatores linguísticos, cognitivos, lógicos e contextuais, simultaneamente, possibilitando o encontro de posições de leitura, as quais viabilizam diferentes olhares e interpretações que serão lançadas ao vestígio, em especial os olhares do profissional indexador na qualidade de leitor e de usuário da informação.

Nesse sentido, Santos et al. (2019) destacam que em tempos de pós-verdade uma informação falsa, no sentido de não coincidir com os fatos reais, pode ser vista como fonte importante para um indexador que acredita e compactua com as ideias apresentadas. Levando em conta que o tratamento temático da informação é uma atividade puramente intelectual, o indexador, no momento da realização de sua atividade, pode (de maneira voluntária ou intencional ou contextual) se deixar levar a partir de suas crenças, trazendo uma espécie de negação ou cessação da verdade que até então acredita. Tal prática sob as lentes da pós-verdade pode inviabilizar ou dificultar a identificação de vestígios e a elucidação de crimes, portanto, faz-se necessária a adoção da postura ética e profissional do Bibliotecário nesse contexto.

Todas as informações apresentadas no resultado desta pesquisa foram apresentadas em outro momento para os profissionais entrevistados, no intuito desses sujeitos apresentarem os seus posicionamentos acerca dos resultados e das descrições das atividades apresentadas neste estudo. Com isso, os sujeitos entrevistados ressaltaram que as operações especificadas nesta pesquisa são válidas para serem desenvolvidas pelo Bibliotecário no intuito de apresentar contribuições significativas no campo da perícia criminal.

Portanto, conforme foi constatado, verifica-se a importância da atuação do Bibliotecário em Órgãos Oficiais de Perícia Criminal, sobretudo, no que concerne às práticas de organização, tratamento e recuperação da informação.

\section{CONSIDERAÇÕES FINAIS}

Em linhas gerais, nesta pesquisa foram apresentadas as principais atividades que podem ser desempenhados pelo profissional da informação em Órgãos Oficiais de Perícia Criminal. Ainda que a ênfase deste estudo esteja na dimensão de explorar esses novos horizontes, faz-se necessário destacar a importância das habilidades, já que essas são necessárias para o profissional saber aplicar esses conhecimentos em suas práticas profissionais. 
Portanto, todas as incumbências apresentadas nesta pesquisa devem estar vinculadas ao saber fazer do Bibliotecário para atender aos aspectos da profissão em qualquer ambiente. Ao agregar as dimensões da competência (conhecimentos, habilidades e atitudes), o exercício profissional se torna promissor em diferentes campos de atuação, inclusive em Órgãos Oficiais de Perícia Criminal.

Diante do exposto, é possível inferir que os objetivos desta pesquisa foram atingidos e que o profissional Bibliotecário pode ser incluído no rol de profissionais aptos a atuar em Órgãos Oficiais de Perícia Criminal. A partir da ótica da Ciência da Informação e da Perícia Criminal, foi possível vislumbrar atividades que podem ser desempenhadas para contribuir com os Peritos Criminais, essas operações estão integradas, sobretudo, no campo da organização, tratamento e recuperação da informação.

Com efeito, o novo campo de atuação revela-se significativo, uma vez que mostra possibilidades e novos horizontes para a profissão. Na medida em que se reflete sobre, percebeu-se que muito pode ser compreendido entre as ciências. A interdisciplinaridade permite que as áreas do conhecimento aqui expostas possam aproveitar de um conhecimento mútuo aprimorando seus serviços com eficiência e eficácia.

Á vista disso, espera-se que esta pesquisa desperte o interesse pela perícia e incentive aos pesquisadores a não ter receio de buscar outras áreas até então não exploradas pelos profissionais da informação, as quais podem parecer, em primeiro momento, não ter relação com a Biblioteconomia e Ciência da Informação. A pesquisa interdisciplinar precisa ser estimulada, uma vez que se desenvolvem novos estudos substanciais ao crescimento da área.

Atrelado a isso, a natureza do trabalho se mostra significativa às entidades como os Conselhos da Classe Profissional (CFB e CRBs) para que possam avaliar novas possibilidades de atuação do Bibliotecário e lutar para fins de conquista desses novos cenários como mercado de trabalho, uma vez que esses profissionais são importantes e podem desempenhar diversos serviços no contexto da sociedade da informação.

Outrossim, este estudo apresenta contribuições para a Biblioteconomia e a Ciência da Informação visando, não somente, apresentar a possibilidade de um novo campo de atuação para o profissional, como também estimular novos estudos interdisciplinares com reflexões e questionamentos sobre o papel do Bibliotecário na sociedade atual.

\section{REFERÊNCIAS}

ALMEIDA JÚNIOR, O. F. Formação, formatação: profissionais da informação produzidos em série. In: VALENTIM, M. L. (Org.). Formação do profissional da informação. São Paulo: Polis, 2002. p. 133-148.

ASSOCIAÇÃO NACIONAL DOS PERITOS CRIMINAIS FEDERAIS. O perito criminal federal. 2017. Disponível em: https://www.apcf.org.br/pericia-criminal/o-perito-criminal-federal. Acesso em: 16 jan. 2020.

BARBALHO, C. R. S.; ROZADOS, H. B. F. Competências do profissional bibliotecário brasileiro: o olhar do Sistema CFB/CRBs. In: ENCONTRO NACIONAL DE PESQUISA EM CIÊNCIA DA INFORMAÇÃO, 9., 2008, São Paulo. Anais eletrônicos [...] São Paulo: USP, 2008. Disponível em: http://enancib.ibict.br/index.php/enancib/ixenancib/paper/viewFile/3087/2213. Acesso em: 16 jan. 2020. 
BARBOSA, R. R. Perspectivas profissionais e educacionais em Biblioteconomia e Ciência da Informação. Ciência da Informação, Brasília, v. 27, n. 1, p.53-60, jan./abr. 1998. Disponível em: http://revista.ibict.br/ciinf/article/view/819/851. Acesso em: 16 jan. 2020.

BORKO, H. Information Science: whats is it? American documentation, [S.I.], v. 19, n. 1, p. 3-5, jan. 1968.

BRASIL. Ministério da Justiça. Secretaria Nacional de Segurança Pública. Portaria n. 82, de 16 julho de 2014. Estabelece as Diretrizes sobre os procedimentos a serem observados no tocante à cadeia de custódia de vestígios. Disponível em:

http://www.lex.com.br/legis 25740023 PORTARIA N 82 DE 16 DE JULHO DE 2014. Acesso em: 16 jan. 2020.

BRASIL. [Constituição (1988)]. Constituição da República Federativa do Brasil de 1988. Brasília, DF: Presidência da República, [2020].

BRASIL. Ministério do Trabalho e do Emprego. Classificação Brasileira de Ocupações. Profissionais da Informação. 2008a. Disponível em:

http://www.mtecbo.gov.br/cbosite/pages/pesquisas/FiltroTabelaAtividade.jsf. Acesso em: 16 jan. 2020.

BRASIL. Ministério do Trabalho e do Emprego. Classificação Brasileira de Ocupações. Peritos Criminais. 2008b. Disponível em:

http://www.mtecbo.gov.br/cbosite/pages/pesquisas/ResultadoFamiliaParticipantes.jsf;jsessi onid=4CMlxglglq6cgy40jR3c6P1m.slave18:mte-cbo. Acesso em: 16 jan. 2020.

BRASIL. Presidência da República. Lei no 3.989, de 3 de outubro de 1941. Código de Processo Penal. Brasília, 2019. Disponível em: http://www.planalto.gov.br/ccivil 03/decretolei/Del3689.htm. Acesso em: 16 jan. 2020.

BRASIL. Presidência da República. Lei n. 11.690, de 9 de junho de 2008. Altera dispositivos do Decreto-Lei no 3.689, de 3 de outubro de 1941 - Código de Processo Penal, relativos à prova, e dá outras providências. 2008c. Disponível em:

http://www.planalto.gov.br/ccivil 03/ Ato2007-2010/2008/Lei/L11690.htm\#art1. Acesso em: 16 jan. 2020.

CUNHA, P. L. L. Implantação de cadeia de custódia de vestígios: implicações para a gestão da polícia civil do distrito federal. 2012. 103 f. Dissertação (Mestrado) - Escola Brasileira de Administração Pública e de Empresas, Centro de Formação Acadêmica e Pesquisa, Rio de Janeiro, 2012. Disponível em:

http://bibliotecadigital.fgv.br/dspace/bitstream/handle/10438/10061/Disserta\%C3\%A7\%C3 \%A30\%20-\%20Pedro\%20Cunha\%20-\%20final.pdf?sequence=1. Acesso em: 16 jan. 2020.

DIAS, E. W.; NAVES, M. M. L. Análise de assunto: teoria e prática. Brasília: Thesaurus, 2007. $116 \mathrm{p}$. 
FARIA, S. et al. Competências do profissional da informação: uma reflexão a partir da Classificação Brasileira de Ocupações. Ciência da Informação, Brasília, v. 34, n. 2, p. 26-33, maio/ago. 2005. http://revista.ibict.br/ciinf/article/download/1087/1192/. Acesso em: 16 jan. 2020.

FLEURY, M. T. L.; FLEURY, A. Construindo o conceito de competência. Revista de Administração Contemporânea, Curitiba, v. 5, 2001. Disponível em:

http://www.scielo.br/scielo.php?script=sci arttext\&pid=S1415-65552001000500010. Acesso em: 16 jan. 2020.

HJØRLAND, B. Information seeking and subject representation: an activity-theoretical approach to Information Science. Westport: Greenwood Press, 1997.

LE COADIC, Y.-F. A Ciência da Informação. Brasília: Briquet de Lemos, 1996.

LIMA, C. J. C. A modernização organizacional da criminalística brasileira: uma proposta. 2012. 85 f. Dissertação (Mestrado) - Escola Brasileira de Administração Pública e de Empresas, Centro de Formação Acadêmica e Pesquisa, Rio de Janeiro, 2012. Disponível em: http://bibliotecadigital.fgv.br/dspace/bitstream/handle/10438/9983/Disserta\%C3\%A7\%C3\% A30\%20Claudio\%20Lima.pdf?sequence=1\&isAllowed=y. Acesso em: 16 jan. 2020.

MARINHO, G. V. Cadeia de custódia da prova pericial: uma exigência no mundo contemporâneo. Revista Segurança, Justiça e Cidadania, [S.I.], n. 9, p .9-25, 2014. Irregular. Disponível em: https://www.justica.gov.br/central-de-conteudo/senasp/anexos/revista9 retificadax.pdf. Acesso em: 18 dez. 2019.

NUCCI, G. S. Código de processo penal comentado. 12. ed. São Paulo: RT, 2012.

OTTONICAR, S. L. C.; BASSETTO, C. L.; FERES, G. G. Papel do gestor sob a ótica da mediação da informação: um estudo de caso em uma empresa de consultoria em gestão empresarial. In: ENCONTRO DE PESQUISA EM INFORMAÇÃO E MEDIAÇÃO, 2., 2015, São Paulo. Anais [...] São Paulo: UNESP, 2015.

RABAGLIO, M. O. Gestão por competências: ferramentas para atração e captação de talentos humanos. Editora QualityMark, 2008.

RASTELI, A.; CAVALCANTE, L. E. A competência em informação e o bibliotecário mediador da leitura em Biblioteca Pública. Encontros Bibli: revista eletrônica de biblioteconomia e ciência da informação, Florianópolis, v. 18, n. 36, p. 157-180, abr. 2013. Disponível em: https://periodicos.ufsc.br/index.php/eb/article/view/1518-2924.2013v18n36p157/24518. Acesso em: 16 jan. 2020.

RODRIGUES, C. V.; SILVA, M. T.; TRUZZI, O. M. S. Perícia Criminal: uma abordagem de serviços. Gestão \& Produção, São Carlos, v. 17, n. 4, p. 843-857, 2010. Disponível em: https://www.scielo.br/pdf/gp/v17n4/a16v17n4.pdf. Acesso em: 16 jan. 2020. 
SANTOS, R. F. Modelos colaborativos de indexação social e a sua aplicabilidade na Base de Dados Referencial de Artigos de Periódicos em Ciência da Informação (BRAPCI). 184 f. Dissertação (Mestrado em Ciência da Informação) - Universidade Federal de Pernambuco, Recife, 2016. Disponível em:

https://repositorio.ufpe.br/bitstream/123456789/17218/1/Raimunda\%20Fernanda\%20dos \%20Santos\%20-\%20Disserta\%c3\%a7\%c3\%a30\%20-\%20PPGCI\%20UFPE\%20-\%20BDTD.pdf. Acesso em: 16 jan. 2020.

SANTOS, R. F. et al. Implicações da pós-verdade na indexação de recursos informacionais. In: BARROS, T. H. B.; TOGNOLI, N. B. Organização do conhecimento responsável: promovendo sociedades democráticas e inclusivas. Belém: Ed. da UFPA, 2019. p. 85-94. Disponível em: https://brapci.inf.br/index.php/res/download/123252. Acesso em: 13 jun. 2020.

SANTOS, R. F.; NEVES, D. A. B.; SOUZA, E. D. A Organização do Conhecimento como domínio de estudo da Ciência da Informação: uma reflexão a partir dos aspectos epistemológicos. In: BARROS, T. H. B.; TOGNOLI, N. B. Organização do conhecimento responsável: promovendo sociedades democráticas e inclusivas. Belém: Ed. da UFPA, 2019. p. 95-104. Disponível em: https://brapci.inf.br/index.php/res/download/123254. Acesso em: 10 jun. 2020. 